\section{Comprehensive Glossary of Terms Used in Toxicology}

by John Duffus, Douglas M. Templeton, and Michael Schwenk

IUPAC, 2017 published by the Royal Society of Chemistry, www.rsc.org

ISBN: 978-1-78262-137-9,

http://dx.doi.org/10.1039/9781782623724

This book represents the culmination, or at least a resting point, in the long-term project that has resulted in five glossaries published as IUPAC Recommendations in Pure and Applied Chemistry (see IUPAC project 2013-006-1-700 for references). The project was initiated in 1989 by the IUPAC Commission on Toxicology to provide a glossary of definitions of terms used in toxicology. The impetus was the recognition that toxic substances (and indeed all substances) are "chemicals", and that there is a need for chemists to understand the mechanisms of toxicity of the substances with which they deal. Both industrial and academic research chemists are faced with an ever-increasing burden in ensuring a safe environment. Even those who may not be trained as chemists must use chemical and toxicological principles in formulating and enforcing legislation introduced to ensure the safe handling of substances throughout their life cycle. Thus, there is a need for an unambiguous vocabulary of terms, both for specialist interpretation of the relevant literature and for warning about hazards and risks that must be controlled and eliminated or minimized.

The starting point of the project was a general glossary of terms in toxicology that collected relevant terms from a variety of sources and revised many of them, with contributions from specialists covering the wide range of knowledge required. IUPAC specialists in terminology advised on the details and the presentation of terms and definitions. The resulting glossary was submitted to Pure and Applied Chemistry for publication following the normal refereeing process for an IUPAC Recommendation [1]. This procedure has been the foundation for future glossary development.

The original glossary was followed by a glossary of terms in toxicokinetics [2]. These two glossaries were later combined and revised, taking into account more recent developments in toxicological science and regulatory activity. Thereafter, it became clear

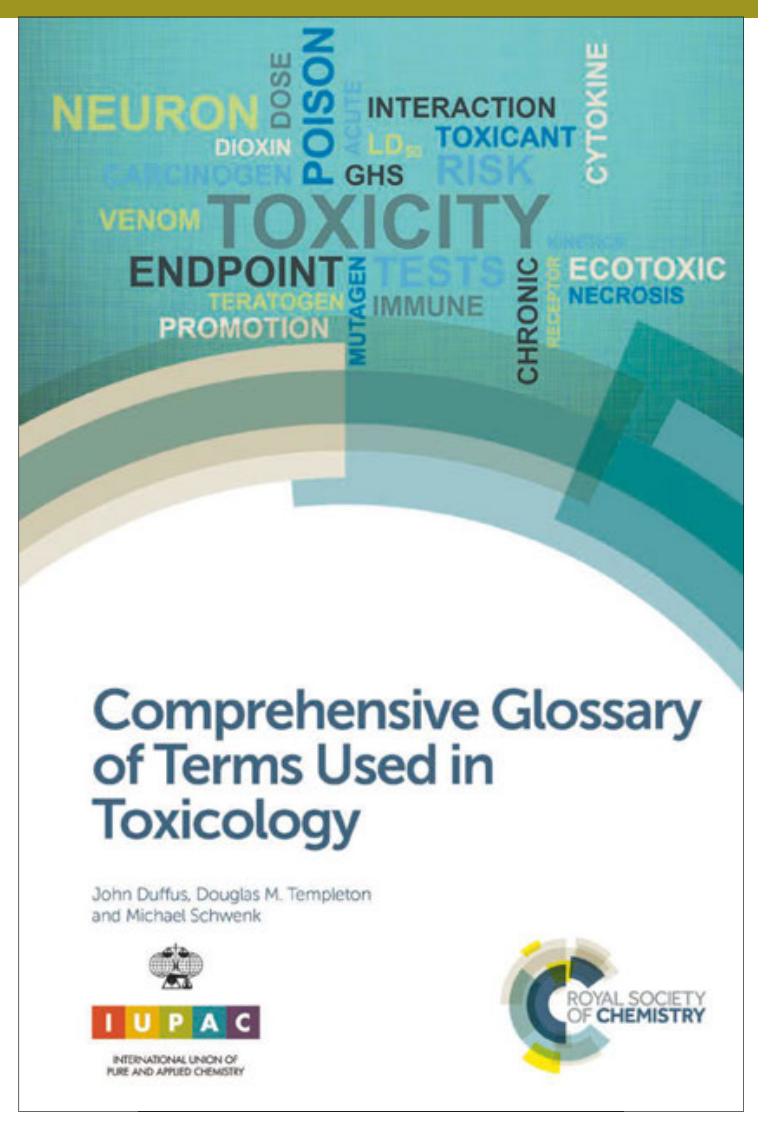

that there were gaps in the coverage of terms related to specialized aspects of toxicology that were becoming increasingly important in their own right. These areas of toxicology were covered in new IUPAC glossaries of the terms used in ecotoxicology, immunotoxicology, neurotoxicology, and reproductive toxicology and teratology. This book consolidates all of these documents and expands their contents with additional terms either newly introduced in toxicology or whose absence in the previous publications we felt should be addressed.

In a compilation of terms that intends to be anything short of a complete word list of the language, decisions of inclusion and exclusion must be made. The vocabulary of toxicology necessarily overlaps with those of medicine, physiology, biochemistry, and ecology, to name a few, and this takes us on occasion into the more specialized realms of cognate disciplines such as anatomy, histology, immunology, neuroscience, molecular biology, epidemiology, and population biology. The authors have also included a number of terms in regulatory toxicology and jurisdictional matters relating to harmful substances. The aim has been to provide a one-stop glossary of terms commonly used in toxicology so that chemists 
reading the toxicological literature will not often need to consult secondary sources in order to understand terms with which they are unfamiliar. Notes are included for many terms; these are not intended to be encyclopedic, but rather to provide clarification or remove ambiguity when a strict definition may not be entirely clear.

\section{References}

1. J. Duffus. Glossary for chemists of terms used in toxicology (IUPAC Recommendations 1993). Pure and Applied Chemistry. 1993, 65(9):2003-2122. https://doi. org/10.1351/pac199365092003

2. M. Nordberg, J. Duffus, and D.M. Templeton. Glossary of terms used in toxicokinetics (IUPAC Recommendations 2003). Pure and Applied Chemistry. 2004, 76(5):10331082. https://doi.org/10.1351/pac200476051033

\section{Reproduced in part from the book preface <http://dx.doi.org/10.1039/9781782623724-FP005>}

\section{Chemistry Teacher International, best practices in chemistry education}

\section{Jan Apotheker, Chair Committee on Chemistry Education, IUPAC \\ Iwona Maciejowska, chair Division on Chemical Education, EuCheMS}

The first issue of Chemistry Teacher International (CTI) will appear in June 2018 and will be presented at the 24th International Conference on Chemistry Engineering (ICCE) in Sydney, Australia. The second issue, to be published in November, will contain material from ICCE, as well as from the upcoming European Conference on

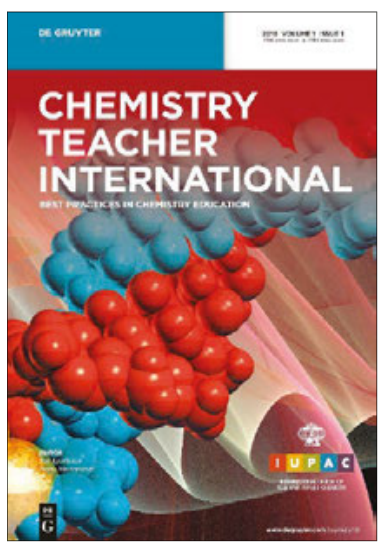
Research in Chemical Education (ECRICE) to be held in September in Warsaw.

Chemistry Teacher International (ISSN 2569-3263) is a new online Open Access journal launched in a collaboration between IUPAC's Committee on Chemistry Education (CCE) and De Gruyter. Articles will be available in HTML and PDF formats. The Editors-in-Chief of the journal are the chair of the CCE, Jan Apotheker, and the chair of the Division of Chemical Education of EuCheMS, Iwona Maciejowska.

The journal aims to publish good practice examples of education from around the world. Activities presented at conferences, such as the Network of InterAsian Chemistry Educators (NICE), African Conference on Research in Chemistry Education (ACRICE), and ECRICE will be sources of material for the journal. Instead of publishing a proceedings book, a special issue of the journal can be published, containing a wealth of material presented at the conference. Of course, activities at ICCE conferences will also be presented. Organizers of Science Olympiads, such as the International Junior Science Olympiad, the European Science Olympiad, and the International Chemistry Olympiad, are strongly invited to discuss the exams from their final rounds in the journal.

\section{History}

For the past two years, CCE has discussed the possibility of starting a journal focused on chemistry education. There had been a publication for some time, which folded more than 10 years ago due to a lack of articles. The format at the time was not very attractive. It did not rise above the level of the magazine of, for example, Jan's golf club, which is even glossier and has a better lay out. It was dittoed or stenciled on regular paper, stapled in the middle, etc.

\section{Background}

In 2012, Marcy Towns and Adam Kraft (Towns \& Kraft, 2012) published an article in which they identified a number of journals focusing on chemistry and science education.

For chemistry they identified:

- Chemistry Education Research and Practice (UK)

- Journal of Chemical Education (USA)

- Biochemistry and Molecular Biology (USA)

- Journal of Research in Science Teaching (USA)

- Science Education (USA)

- Research in Science Education (AUS)

- International Journal of Science Education (UK)

- The Chemical Educator (USA)

- Australian Journal of Education in Chemistry (AUS)

- Education in Chemistry (UK)

- Educacion Química (MEX)

For science they found:

- Eurasia Journal of Mathematics, Science \& Technology Education (INT) 